\title{
Use of Drill Cuttings for Road Building
}

\author{
Anton Sergeevich Vlasov ${ }^{1}$ and Konstantin Georgievich Pugin ${ }^{1,2}$ \\ ${ }^{1}$ FSBEI HE "Perm National Research Polytechnic University", Perm, Russia \\ ${ }^{2}$ FSBEl HE «Perm State Agro-Technological University named after Academician D.N. \\ Pryanishnikov», Perm, Russia
}

\section{Abstract}

The negative impact on the environment from drill cuttings resulting from drilling wells for oil production is assessed in this article. Environmental hazards are contaminants such as petroleum products, drilling fluid reagents, and chemical compounds of heavy metals that make up drill cuttings. To assess the negative impact, the heavy metal content indicators and chemical analysis parameters of drill cuttings were determined. It has been established that there are no excesses in the standards for the content of heavy metals in drill cuttings. The results of chemical analysis showed that there are excesses in values: MPC (Maximum Permissible Concentrations), COD (Chemical Oxygen Demand), oil content, solids, hardness, magnesium and calcium ions, chlorides.

Corresponding Author: Anton Sergeevich Vlasov anton-vlasov@inbox.ru

Published: 31 December 2020

Publishing services provided by Knowledge E

(c) Anton Sergeevich Vlasov and Konstantin Georgievich

Pugin. This article is distributed under the terms of the Commons Attribution License, which permits unrestricted use and redistribution provided that the original author and source are credited.

Selection and Peer-review under the responsibility of the TECHNOGEN-2019 Conference Committee.

\section{G OPEN ACCESS}

In Russia, during the development of oil fields, a large number of drilling operations are carried out during which drill cuttings (hereinafter referred to as DC) are formed, which is an aqueous suspension, the solid part of which consists of products from the destruction of rocks of the face and borehole walls, products of abrasion of the drill string and casing, clay minerals (when washing with a clay solution). DC are large-scale waste and a source of significant environmental pollution [1]. About 300 thousand of such waste is formed annually. More than 95 million DC have been accumulated in Russia [2].

Organizations engaged in drilling operations should place the resulting DC in special drilling barns. At the same time, a large number of organizations violate this requirement and place DC on unprepared sites, which forms a negative impact on environmental objects. 
The mineralogical composition of DC depends on the lithological composition of the rocks being drilled and changes as the well deepens and the place of extraction of minerals. The granulometric composition of $D C$ is determined by the type and diameter of the rock cutting tool, the mechanical properties of the rock, and the properties of the flushing fluid. DC according to the classification of the FCCW (Federal Classification Catalog of Wastes) are classified as hazard class IV.

The degree of contamination depends on the type of drilling fluid that is required for drilling. Drilling fluid is a complex multicomponent disperse system of suspension, emulsion and aerated fluids used for flushing wells during drilling. In practice, drilling fluids are used on aqueous (industrial water, salt and hydrogel solutions, polymer, polymerclay and clay solutions) and hydrocarbon (lime-bitumen, invert emulsion) substrates. Previously, an oil-based solution was used, but due to its high toxicity it was banned in almost all countries [3].

The total composition of DC includes components: water - 25\%; cuttings - $60 \%$; chlorides - up to $0.5 \%$; heavy metals - $6 \%$; drilling fluid reagents - $8 \%$; other compounds $-0.5 \%$

An analysis of the scientific literature showed that the main impact is on the lithosphere due to the inclusion of oil and its fractions, which are considered the main toxic agent, in DC composition. Also dangerous are toxic substances added to the drilling fluid in the form of various chemical reagents: ether-retrievable compounds, cellulosebased polymer, clay powder, KMC-600, xentan gum, lignin and sulfolignin, etc. Reagents are needed to reduce the water loss of the formation, to reduce the viscosity of the solution.

DC are stored in a barn or barn-free method. For their placement, land plots are seized, while the flora and fauna around the storages are destroyed.

In the works of the authors Vasilyev $\mathrm{A}$. and $\mathrm{Xu} \mathrm{T}$. it was shown that when the waterproofing of the slurry barn is disturbed, the productivity of the soil cover decreases, and groundwater pollution occurs $[4,5]$. The toxins contained in the sludge are washed away into the ground by atmospheric precipitation and, then, are transported into the rivers by groundwater. As a result, inhibition and suppression of organic life, a change in the composition of biocenoses.

In the works of the authors Mostavi E. and Kujawska J. air pollution is shown, which consists in the fact that, under the influence of direct sunlight, intense evaporation of light hydrocarbon fractions occurs $[6,7]$.

In the works of the authors Junttila J. and Arley S. Rossi data on the effect on soil, flora and fauna, which consists mainly in oil pollution, are given [8,9]. Violated the air regime and water properties of soils. There is a decrease in the number of 
cellulose-degrading microorganisms that assimilate nitrogen compounds. Inhibition of redox enzymatic processes occurs, which reduces soil fertility and biological activity.

Thus, DC have a complex negative impact on humans and natural ecosystems. One of the practical tasks is to minimize the negative impact of DC on the environment.

In this regard, laboratory studies of DC were carried out to determine physical and chemical parameters and the content of heavy metals, and based on the results obtained, possible ways of its use were outlined. DC were sampled at several fields in the Russian Federation (see Table 1): Sample No. 1 - Orenburg Oblast, Sample No. 2 - Tomsk Oblast, Sample No. 3 - Yamal-Nenets Autonomous Okrug. It has been established that there are no excess standards for the content of heavy metals in mobile form.

TABLE 1: The content of heavy metals in DC samples

\begin{tabular}{|c|c|c|c|c|c|c|c|}
\hline \multirow[t]{2}{*}{ Name } & \multicolumn{7}{|c|}{ The content of heavy metals, $\mathrm{mg} / \mathrm{kg}$} \\
\hline & Cadmium & Chrome & Nickel & Cobalt & Plumbum & Cuprum & Manganese \\
\hline DC sample No. 1 & $\begin{array}{c}\text { less than } \\
0,2\end{array}$ & $1,8 \pm 0,4$ & $0,60 \pm 0,18$ & less than 4 & less than 5 & $2,0 \pm 0,5$ & $23 \pm 4$ \\
\hline $\begin{array}{l}\text { DC sample No. } \\
2\end{array}$ & $\begin{array}{c}\text { less than } \\
0,2\end{array}$ & $0,74 \pm 0,23$ & $3,0 \pm 0,8$ & $1,2 \pm 0.4$ & $3,4 \pm 0,9$ & $3,3 \pm 0,8$ & $51 \pm 8$ \\
\hline $\begin{array}{l}\text { DC sample No. } \\
3\end{array}$ & $\begin{array}{c}\text { less than } \\
0,2\end{array}$ & $1,08 \pm 0,27$ & $2,3 \pm 0,6$ & $0,96 \pm 0,29$ & $1,8 \pm 0,5$ & $0,62 \pm 0,19$ & 112 \\
\hline $\begin{array}{l}\text { The value of the } \\
\text { permissible } \\
\text { value (PND F } \\
\text { 16.1: } 2.3 \text { : } \\
\text { 3.50-08) }\end{array}$ & 1,0 & 6,0 & 4,0 & 5,0 & 6,0 & 3,0 & 600,0 \\
\hline
\end{tabular}

Water extracts were also prepared from DC samples dried at $105^{\circ} \mathrm{C}$ to constant weight to determine chemical parameters. An analysis of the results (see Table 2) of quantitative chemical analysis showed that there are excesses in values: MPC (Maximum Permissible Concentrations of harmful substances in the waters of fishery water bodies), COD (Chemical Oxygen Demand), oil products, solids, hardness, magnesium ions and calcium, chlorides.

In order to reduce the negative impact, it was proposed to use DC resource potential in the construction of roads. Two directions of DC utilization were chosen: the use of $D C$ for the construction of the foundation of the road and the production of material based on DC to strengthen the slopes.

Initial studies on the production of technoground based on DC sample No. 1 were carried out. Used dried at $105^{\circ} \mathrm{C}$ to constant weight DC. In the first series of the experiment, mixtures with different contents of cement grade PC-400 and water glass 
TABLE 2: Quantitative Chemical Analysis Results

\begin{tabular}{|c|c|c|c|c|c|}
\hline \multirow{2}{*}{$\begin{array}{l}\text { Defined } \\
\text { characteristics }\end{array}$} & \multirow[t]{2}{*}{ Units } & \multicolumn{3}{|c|}{ Analysis results } & \multirow{2}{*}{$\begin{array}{c}\text { Limit of } \\
\text { permissible } \\
\text { concentrations }\end{array}$} \\
\hline & & DC sample No. 1 & $\begin{array}{c}\text { DC sample } \\
\text { No. } 2\end{array}$ & $\begin{array}{l}\text { DC sample } \\
\text { No. } 3\end{array}$ & \\
\hline $\mathrm{pH}$ & un.pH & $6,9 \pm 0,05$ & $7,1 \pm 0,05$ & $7,8 \pm 0,05$ & $6,5-9,0$ \\
\hline $\begin{array}{l}\text { Chemical } \\
\text { Oxygen } \\
\text { Demand }\end{array}$ & $\mathrm{mgO}_{2} / \mathrm{dm}^{3}$ & $1300 \pm 65,0$ & $278 \pm 13,9$ & $444 \pm 22,2$ & 30 \\
\hline Oil product & $\mathrm{mg} / \mathrm{dm}^{3}$ & $4,4 \pm 0,88$ & $2 \pm 0,4$ & $2,70 \pm 0,9$ & 0,05 \\
\hline Dry residue & $\mathrm{mg} / \mathrm{dm}^{3}$ & $1590,0 \pm 159,0$ & $1110 \pm 111,0$ & $1800 \pm 180,0$ & 1000 \\
\hline Rigidity & Mmol-eq/dm 3 & $60 \pm 3,0$ & $3,5 \pm 0,18$ & $23 \pm 1,15$ & 10,0 \\
\hline Calcium ion & $\mathrm{mg} / \mathrm{dm}^{3}$ & $800 \pm 40,0$ & $46,70 \pm 2,4$ & $306 \pm 15,3$ & 180,0 \\
\hline Magnesium ion & $\mathrm{mg} / \mathrm{dm}^{3}$ & $240 \pm 12,0$ & $14 \pm 0,7$ & $92 \pm 4,6$ & 40,0 \\
\hline Chlorides & $\mathrm{mg} / \mathrm{dm}^{3}$ & $1411,1 \pm 70,6$ & $258 \pm 12,9$ & $1650 \pm 82,5$ & 300 \\
\hline
\end{tabular}

(diluted with water in a ratio of 1:5) and with the addition of a small amount of water (10\% of the mixture of cement and sand) were mixed.

After five days with visual inspection, it was found that samples with a cement content of more than $25 \%$ and less than $15 \%$ were covered with cracks and were very fragile upon tactile contact. After that, the samples were placed in water, and after 5 minutes, the destruction of the samples to a lumpy state began. After keeping the samples in water for a day, lumpy elements of various fractions were obtained: 2-20 mm. (see Figure 1). Based on this, it is proposed to use the resulting lumpy material (technoground) for placement in a barn and further excavation for filling embankments and strengthening soil.

A series of experiments with various compositions was carried out, using wet DC (humidity $60 \%$ ), water was not added, since the mixture acquired the necessary creamy shape when mixing the components, according to the technological process. Samples were kept for five days. During visual inspection and tactile contact, it was established that the sample with the following component composition has the most stable strength characteristics: cement - $20 \%$, DC - $80 \%$, liquid glass - $2 \%$ over $100 \%$ of the mixture (see Figure 2).

Based on the preliminary analysis, the necessary proportions of the mixtures were selected, and refinement laboratory studies are currently underway to assess the compliance of the products with regulatory documents. Indicators are determined: compressive strength, elastic modulus, particle size distribution of the mixture, frost resistance, abrasion, etc. 


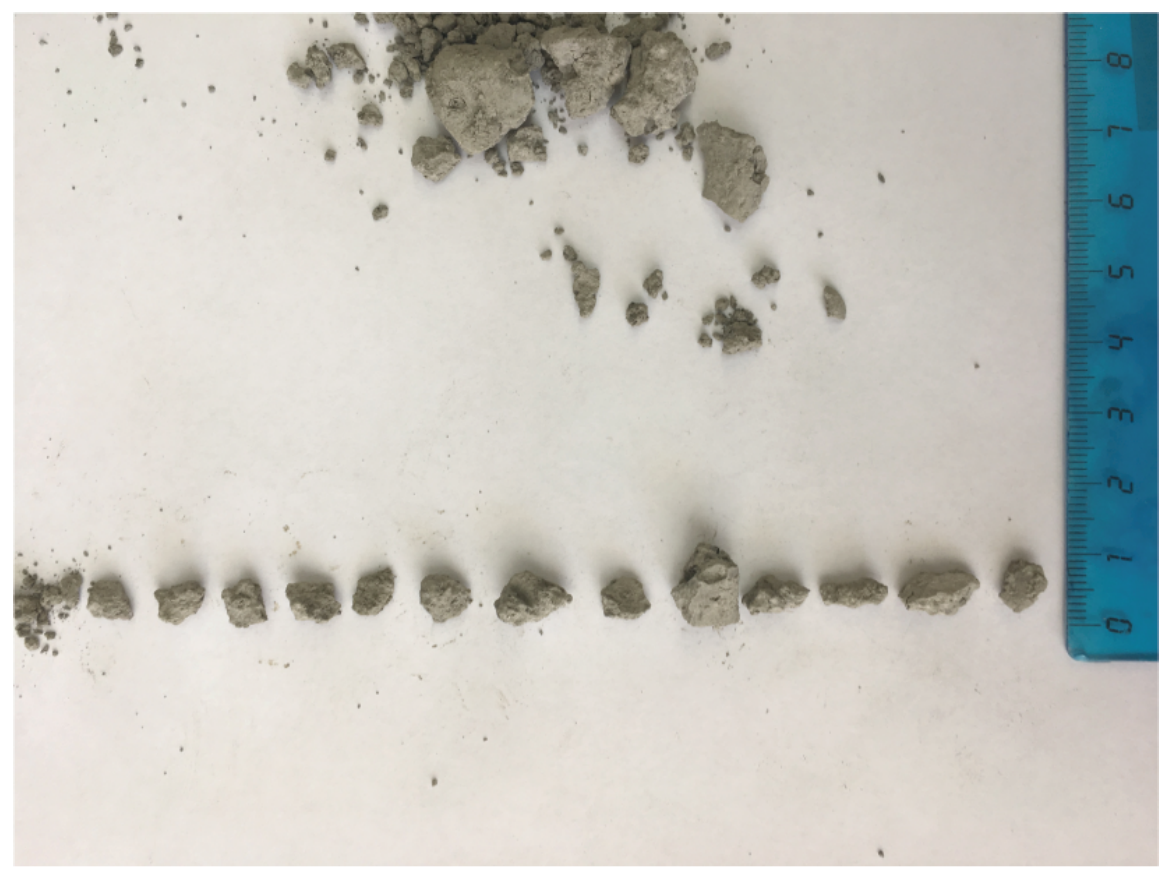

Figure 1: Lumpy material obtained

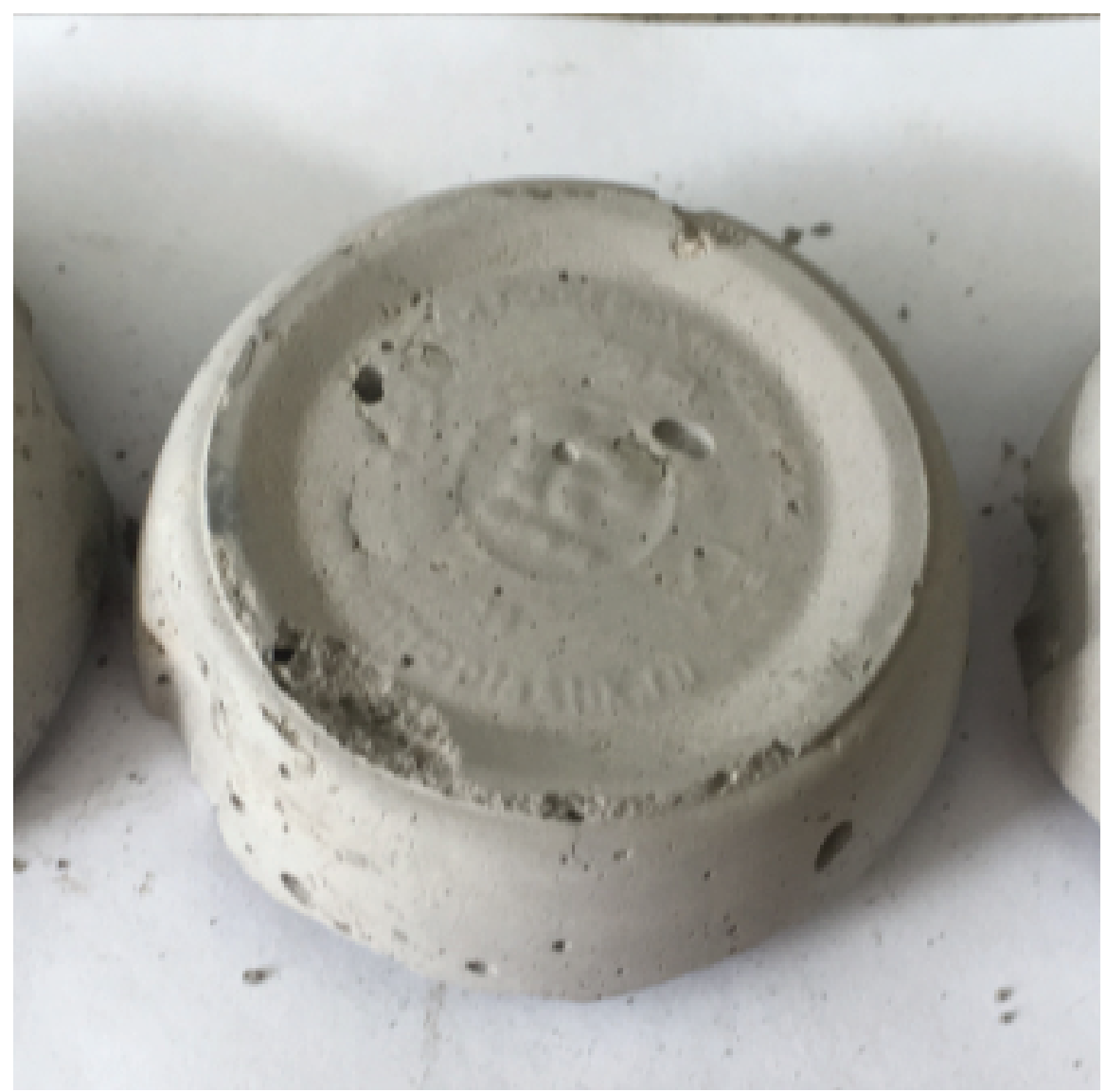

Figure 2: Appearance of the obtained sample after aging for five days 


\section{References}

[1] Hejna, A., et al. (2018). Structure and Performance Properties of EnvironmentallyFriendly Biocomposites Based on Poly( $\varepsilon$-Caprolactone) Modified with Copper Slag and Shale Drill Cuttings Wastes. Science of the Total Environment, issue 640, pp. 1320-1331.

[2] Guryeva, V. A. (2015). Drill Cuttings in the Production of Building Ceramics. Building materials, issue 4, pp. 75-77.

[3] Reuben, N. O. and Perez, P. A. (2018). Towards Enhancing Sustainable Reuse of PreTreated Drill Cuttings for Construction Purposes by Near-Infrared Analysis: A Review. Journal of Civil Engineering and Construction Technology, issue 9, pp. 19-39.

[4] Vasilyev, A. V. (2014). Environmental Impact of Drill Cuttings and Approaches to their Processing. Bulletin of the Samara Scientific Center of the Russian Academy of Sciences, issue 5, pp. 308-313.

[5] Xu, T., et al. (2018). Heavy Metal Pollution of Oil-Based Drill Cuttings at a Shale Gas Drilling Field in Chongqing, China: A Human Health Risk Assessment for the Workers. Ecotoxicology and Environmental Safety, issue 165, pp. 160-163.

[6] Mostavi, E., Asadi, S. and Ugochukwu, E. (2015). Feasibility Study of the Potential Use of Drill Cuttings in Concrete. International Conference on Sustainable Design, Engineering and Construction, issue 118, pp. 1015-1023.

[7] Kujawska, J., Malgorzata, P. and Wojciech, C. (2015). Potential Influence of Drill Cuttings Landfill on Groundwater Quality-Comparison of Leaching Tests Results and Groundwater Composition. Desalination and Water Treatment, vol. 57, pp. 1409-1419.

[8] Junttila, J., Dijkstra, N. and Aagaard-Sørensen, S. (2018). Spreading of Drill Cuttings and Sediment Recovery of Three Exploration Wells of Different Ages, SW Barents Sea, Norway. Marine Pollution Bulletin, issue 135, pp. 224-238.

[9] Rossi, A. S., et al. (2017). Kinetics of Microwave Heating and Drying of Drilling Fluids and Drill Cuttings. Drying Technology, issue 35, pp. 1129-1140. 